\title{
Cornelia De Lange Syndrome and Dental Treatment: A Case Report
}

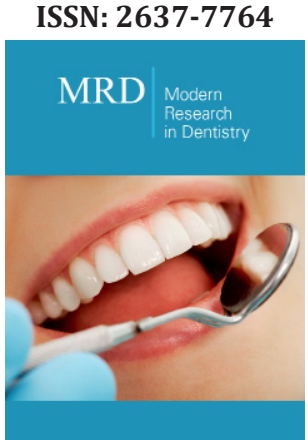

*Corresponding author: Chaza Kouchaji, Pediatric dental department, Faculty of dental medicine, Damascus university, Syria

Submission: 㭰 August 08, 2020

Published: 眥 March 16, 2021

Volume 6 - Issue 2

How to cite this article: Chaza Kouchaji, Maram Mohamad Samir al Saitary. Cornelia De Lange Syndrome and Dental Treatment: A Case Report. Mod Res Dent. 6(2). MRD. 000631. 2021.

DOI: 10.31031/MRD.2021.06.000631

Copyright@ Chaza Kouchaji, This article is distributed under the terms of the Creative Commons Attribution 4.0 International License, which permits unrestricted use and redistribution provided that the original author and source are credited.
Chaza Kouchaji* and Maram Mohamad Samir al Saitary

Pediatric dental department, Faculty of dental medicine, Damascus university, Syria

\section{Abstract}

Cornelia De Lange Syndrome is a multisystemic disease with expressing variable physical, cognitive, and behavioral characteristics. It is a genetic disorder that affects many organs, leading to various clinical presentations. In this case presentation we will report a case of CdLS phenotype, along with extra and intra oral finding and radiographic, then dental management and its follow up.

\section{Introduction}

\section{History}

Previously, in 1849, the anatomist Willem Vrolik (1801-1863) reported a case as an extreme example of oligodactyly, and the German doctor Brachmann published, in 1916, a case of symmetric monodactyly, antecubital webbing, dwarfism, cervical ribs, and hirsutism. Throughout history, other names for the syndrome have included Amsterdam dwarfism, Bushy syndrome, or Brachmann syndrome [1] CdLS is a multisystemic disease with expressing variable physical, cognitive, and behavioral characteristics. It is a genetic disorder that affects many organs, leading to various clinical presentations (1).

It is thought that this syndrome was first described in 1916 by Dr. W. Brachmann, a Dutch pediatrician after which this syndrome is occasionally named (Brachmann-De Lange Syndrome). However, the syndrome is most commonly named after Prof. Cornelia De Lange (1871-1950) who reported her first two cases in 1933 (Figure 1) and presented an account of this syndrome in 1941 in the meeting of the Neurology Society of Amsterdam (2).

\section{Frequency}

This syndrome affects 1 in 10000 to 30000 newborn [2].

\section{Genotypes}

Cornelia de Lange Syndrome (CdLS) has five distinctive genotypes numbered from 1 to 5 with CdLS 1 is the most common which contributes $50-60 \%$ of cases. The Table 1 shows the five different genotypes with their mutation locations, phenotype and their MIM numbers in addition to their related genes and genes MIM numbers and their inheritance types [2]. The affected genes (NIPBL, SMC1A, SMC3, RAD21, and HDAC8) all code proteins which are part of the cohesion pathways.

Table 1: Phenotypes of CdLS with their related gene locations and MIM numbers. (www.omim.org).

\begin{tabular}{|c|c|c|c|c|c|}
\hline Location & Phenotype & $\begin{array}{c}\text { Phenotype } \\
\text { MIM Number }\end{array}$ & Inheritance & $\begin{array}{c}\text { Gene } \backslash \\
\text { Locus }\end{array}$ & $\begin{array}{c}\text { Gene } \backslash \text { Locus } \\
\text { MIM Number }\end{array}$ \\
\hline $15 p 13.2$ & $\begin{array}{c}\text { Cornelia De Lange Syn- } \\
\text { drome 1 }\end{array}$ & 12270 & AD & NIPBL & 608667 \\
\hline Xp11.22 & $\begin{array}{c}\text { Cornelia De Lange Syn- } \\
\text { drome 2 }\end{array}$ & 300590 & XLD & SMC1A & 300040 \\
\hline $10 q 25.2$ & $\begin{array}{c}\text { Cornelia De Lange Syn- } \\
\text { drome 3 }\end{array}$ & 610759 & AD & SMC3 & 606062 \\
\hline $8 q 24.11$ & $\begin{array}{c}\text { Cornelia De Lange Syn- } \\
\text { drome 4 }\end{array}$ & 614701 & AD & RAD21 & 606462 \\
\hline Xq13.1 & $\begin{array}{c}\text { Cornelia De Lange Syn- } \\
\text { drome 5 }\end{array}$ & 300882 & XLD & HDAC8 & 300269 \\
\hline
\end{tabular}




\section{Clinical manifestations}

This syndrome consists of multiple skeletal deformities with moderate to severe mental retardation associated with facial dysmorphism. There is usually intrauterine growth retardation demonstrated by low birth weight [3] as well as postnatal growth retardation demonstrated by short stature [4]. This can be at least partially attributed to feeding difficulties in the early childhood. The latter is one of the most common early demonstrations of the syndrome and mainly due to Gastro-Esophageal Reflux Disease (GERD) [4].

The main skeletal abnormalities include: micromilia, clinodactyly, single transverse palmar crease, proximal implantation of thumbs, syndactyly of $2^{\text {nd }}$ and $3^{\text {rd }}$ toes.

Regarding the mental retardation, most cases can categorized as profoundly disabled [5]. the Intellectual Quotient ranges from below 30 to 86 (average: 53) with initial hypertonicity as the most stable finding that deter their performance.

Facial dysmorphism findings include microcephaly, highly arched bushy eyebrows with synophrys [4], long thick eyelashes, depressed nasal bridge, anteverted nostrils [4], and low set posteriorly rotated deformed ears [3] with hearing loss [4].

\section{Dental manifestations}

Extra-oral manifestations include: long shallow philtrum with prominent symphysis, down slanted mouth angles, and microganthia [4].

Intra-oral examination shows usually highly arched palate with delayed eruption [4]. From the pedodontics perspective, it is worth to mention main behavioral symptoms. CdLS children are usually mentally retarded with hypertonicity and hyperactivity with attention problems. Although they are generally shy but the may present combative or self-injurious behavior [4,5].

\section{Case Report}

In this paper, we report a case of CdLS phenotype, along with extra and intra oral finding and radiographic, then dental management and its follow up.

\section{Presentation}

9 years old girl with phonation difficulties and hearing, was brought to the Pediatric Dentistry Clinic, Damascus University, Damascus, Syria. The later was treated with unclear surgical procedure at age of 2 years.as well as a dysmorphic face since birth which was not fully investigated.

This girl was complaining of continuous pain of $2^{\text {nd }}$ primary lower molars.

\section{Extra-oral findings}

Well noticed face dysmorphism with low frontal hairline, highly arched thick eyebrows, widely spaced eyes (hypertelorism) with mild epicanthal fold, triangular face, anteroverted nostrils, shallow protruded philtrum and wide mouth with downwards slanting corners (Figure 1). No skeletal deformities. We found the facial findings to be suggestive of Cornelia de Lange Syndrome (CdLS).

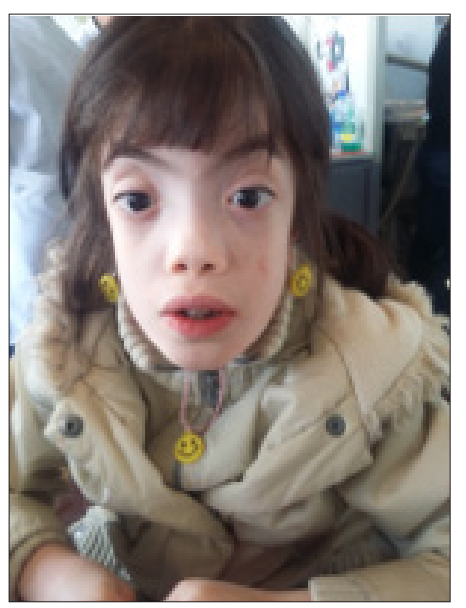

Figure 1: Wide mouth with downwards slanting corners.

\section{Intra-oral findings}

Highly arched palate, significant overlap, narrowed mandibular and maxillary arches, crowded teeth. (Figure 2-4). Type I caries lesions in 54, 64, 74, and 84.

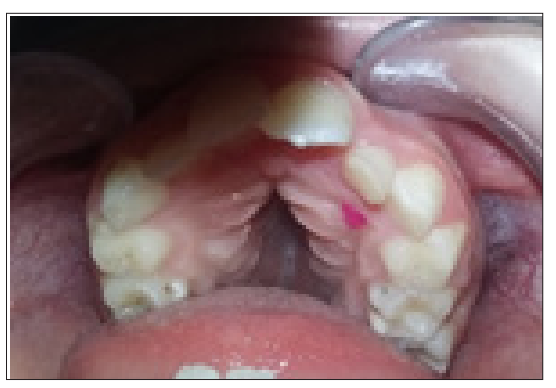

Figure 2: Highly arched palate and significant overlap.

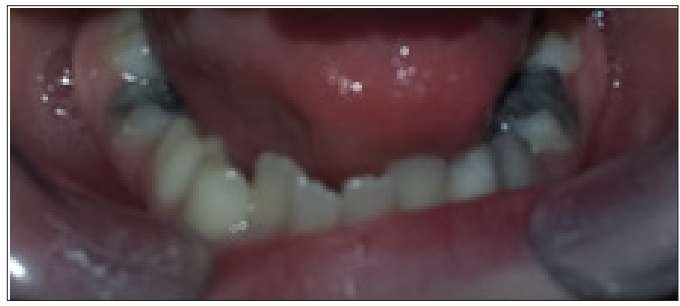

Figure 3: Narrowed mandibular and maxillary arches.

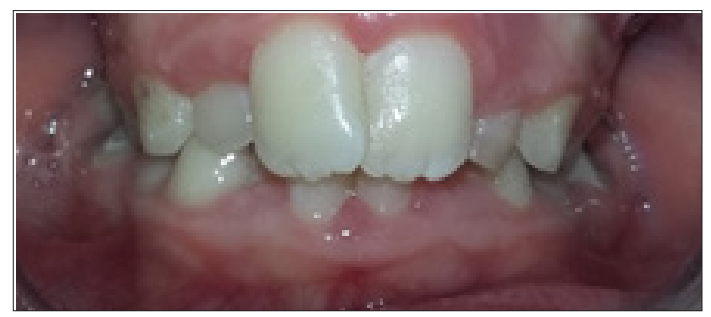

Figure 4: Crowded teeth. 


\section{Radiological findings}

Panoramic X ray showed loss of $2^{\text {nd }}$ premolar buds (Figure 5).

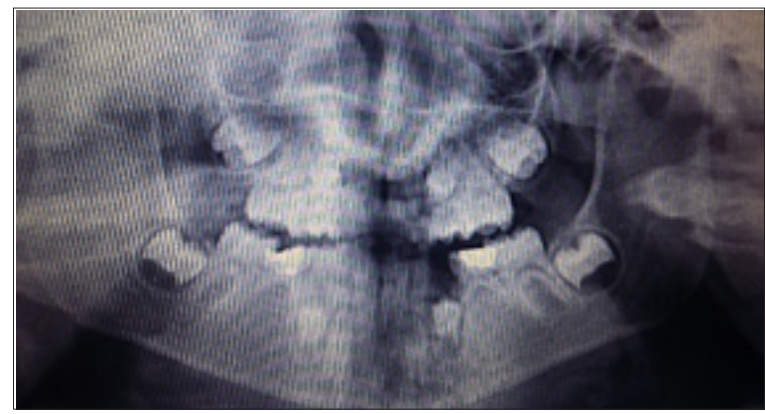

Figure 5: Panoramic $X$ ray showed loss of 2 nd premolar buds.

\section{Management}

A. Extraction of 74 and 85.

B. Restorative treatment with Glass-Ionomer Composite fillings of 54, 55, and 64 .

C. Root canal treatment with stainless steel crown under intravenous sedation.

\section{Follow-up}

The patient was followed up one month later clinically as the restorations and root canal treatment found satisfactory esthetically and functionally. The extractions site showed good healing and uncomplicated. Also, a follow up panoramic $\mathrm{X}$ ray was performed (Figure 6). Which showed no X ray transparencies?

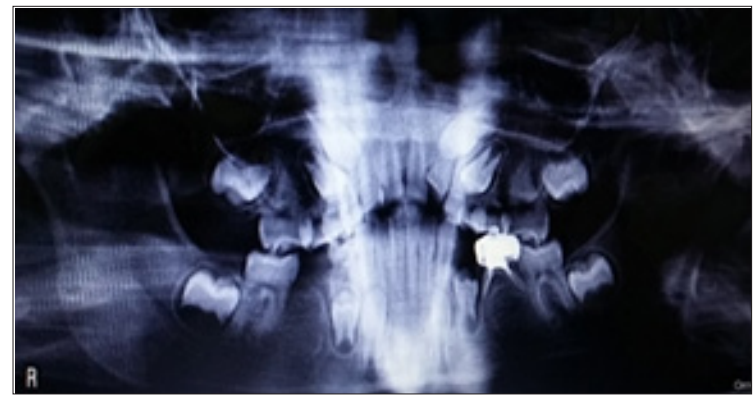

Figure 6: A follow up of panoramic $X$ ray.

\section{References}

1. Cascella M, Muzio MR (2020) Cornelia de Lange Syndrome. Book from StatPearls Publishing, Treasure Island, Florida, USA.

2. Boyle MI, Jespersgaard C, Brøndum Nielsen K, Bisgaard AM, Tümer Z (2015) Cornelia de Lange Syndrome. Clin Genet 88(1): 1-12.

3. Hei M, Gao X, Wu L (2018) Clinical and genetic study of 20 patients from China with Cornelia de Lange Syndrome. BMC Pediatr 18(1): 64.

4. Kline AD, Grados M, Sponseller P, Lev y HP, Blagowidow N, et al. (2007) Natural history of aging in Cornelia de Lange syndrome. Am J Med Genet C Semin Med Genet 145C(3): 248-60.

5. Mulder PA, Huisman SA, Hennekam RC, Oliver C, van Balkom ID, et al. (2017) Behaviour in Cornelia de Lange syndrome: a systematic review. Dev Med Child Neurol 59(4): 361-366. 